\title{
COMPARAÇÃO E VALIDAÇÃO DA MODELAGEM ESPACIAL DE RISCOS DE INCÊNDIOS CONSIDERANDO DIFERENTES MÉTODOS DE PREDIÇÃO
}

\section{Comparison and Validation of Spatial Modeling of Fire Risks Considering Different Prediction Methods}

\author{
André Luiz Sá de Oliveira ${ }^{1}$ \\ Marcelo Antônio Nero² \\ João Rodrigues Tavares Júnior ${ }^{3}$ \\ Ana Lúcia Bezerra Candeias ${ }^{3}$
}

Rodrigo Affonso de Albuquerque Nóbrega ${ }^{2}$

\begin{abstract}
1 Núcleo de Estatística e Geoprocessamento - NEG, Fundação Oswaldo Cruz - Fiocruz Pernambuco/ Instituto Aggeu Magalhães. Recife, Pernambuco, Brasil. E-mail: andre.sa@cpqam.fiocruz.br

2 Centro de Geociências, Departamento de Cartografia, Universidade Federal de Minas Gerais - UFMG. Belo Horizonte, Minas Gerais, Brasil. E-mail: marcelo.nero@gmail.com; raanobrega@ufmg.br

3 Centro de Tecnologia e Geociências - CTG, Departamento de Engenharia Cartográfica - DeCart, Universidade Federal de Pernambuco - UFPE. Recife, Pernambuco, Brasil. E-mail: joaoufpe@gmail.com; analucia@ufpe.br
\end{abstract}

\begin{abstract}
:
The environmental problems of fires change the dynamics of the planet modifying and destroying their cycles and ecosystems. The human being is responsible for almost all the fires, but he is also protagonist of prevention initiatives. Thus, it becomes necessary to plan actions to combat these environmental damages. Since the geographic location is a important attribute, this research aims to support prevention and control of fires generating and validating maps with prediction risk of fire models applied in João Pessoa city. The data were modeled, processed, handled and analyzed in ArcGIS software v10.0 and Matlab, as well as the generation and overlay of thematic maps using multicriteria analysis, weighting the variables and fuzzy logic. In the next step, it was made the data validation considering the real data and the results demonstrated that the templates generated with the aid of fuzzy logic showed the coefficient of determination above $85 \%$. The rainfall variable was the factor that contributed significantly to the models having greater reliability. This variable was not used and not specifically recommended in other methods compared in this study. The factors that contributed to the high degree of vulnerability risk of fires: high slope, vegetation, areas of high concentration of people, subnormal agglomerations and regions within the influence of the road network and hydrography. Finally, this study aimed to contribute to the decision making of the environment, social security and defense managers quickly and accurately using a few variables and low cost.
\end{abstract}


Keywords: Fires; Geoprocessing; Risk maps; Validation.

\section{Resumo:}

Os problemas ambientais decorrentes dos incêndios alteram a dinâmica do planeta modificando seus ciclos e destruindo ecossistemas. O homem é responsável por quase a totalidade das queimadas, sendo ele também protagonista das iniciativas de prevenção. Dessa maneira, torna-se necessário um planejamento de ações ao combate desses danos ambientais. Uma vez que a localização geográfica é importante atributo, esta pesquisa objetiva apoiar medidas de prevenção e controle de incêndios gerando e validando mapas com modelos preditivos de riscos de incêndios no município de João Pessoa - PB. Os dados foram modelados, processados, manipulados e analisados no software ArcGIS v10.0 e Matlab, bem como a geração e overlay de mapas temáticos através de análise multicritério, ponderação das variáveis e lógica fuzzy. Foi realizada a validação dos modelos considerando dados reais, onde os resultados demonstraram que os modelos gerados com o auxílio da lógica fuzzy apresentaram um coeficiente de determinação acima de $85 \%$. A variável pluviometria contribuiu significativamente para que os modelos apresentassem maior confiabilidade. Essa variável não foi utilizada e nem recomendada especificamente em outras metodologias comparadas nessa pesquisa. Os fatores que contribuíram para o alto grau de vulnerabilidade de risco de incêndios: alta declividade, presença de vegetação, áreas de alta concentração de pessoas, aglomerados subnormais e regiões dentro da influência da rede viária e hidrografia. Por fim, esse trabalho teve o intuito de contribuir na tomada de decisão dos gestores de meio ambiente, segurança e defesa social de forma rápida e precisa com recurso a poucas variáveis e baixo custo.

Palavras-chave: Incêndios; Geoprocessamento; Mapas de risco; Validação.

\section{Introdução}

O fogo é um agente com vasta capacidade de alteração do ambiente, modificando ecossistemas e as formas de vida em todo o mundo (Koproski, 2007). Os incêndios, casuais ou propositados, resultam em grandes prejuízos, tanto ao meio ambiente quanto ao próprio homem e as suas atividades econômicas. Primeiramente, devem-se detectar os agentes causadores dos incêndios, o que é amplamente comentado em Ambiente Brasil (2006) e Nogueira (2002).

Os incêndios são uma das maiores fontes de danos às florestas e que tem ocorrido também de modo criminoso causando danos e perdas irreparáveis do ponto de vista ecológico e econômico. A falta de conhecimento dificulta o estabelecimento de políticas adequadas de prevenção e combate aos incêndios. A utilização de técnicas de prevenção, bem como a realização de um planejamento estratégico de combate, é alternativa viável para redução das ocorrências (Ferraz e Vetorazzi, 2003). Com respeito à detecção e localização dos focos de incêndio existem diversos trabalhos, tais como Remmel e Pereira (2001), Alves e Nóbrega (2011) e com base em leis oficiais (Minas Gerais, 2005). Imagens de satélite apresentam retratos periódicos do espaço, aumentando a capacidade de detectar modificações e atualizar banco de dados geográficos (Carvalho e Câmara, 2002). Porém, os exemplos supracitados realizam, basicamente, funções de detecção de incêndios, não levando em conta a prevenção conforme abordagem de Clemente (2008). 
Alguns países europeus criaram métodos para a produção de mapas de risco de incêndio florestal possibilitando a elaboração de um plano de prevenção mediante aos órgãos gestores. Existem diversos projetos e zoneamento de risco através de mapas, como nos trabalhos recentes de Oliveira et al (2012), Zahng et al (2011), Ribeiro et al (2008), Ribeiro (2009) e Prudente (2010).

No combate aos incêndios, o geoprocessamento tem sido utilizado amplamente. Exemplos de aplicações podem ser apresentados, tais como: geração de mapas temáticos estratégicos de combate ao incêndio, com a localização de rede viária, hidrografia, centros urbanos e também na obtenção de cartas de risco de incêndios (Silva et al, 2013; Lourenço et al, 2012; Pierce et al, 2012; Koproski et al, 2011, 2008; Koproski, 2007; Chuvieco et al, 2010; Chou, 2010; Oliveira, 2002).

O uso de técnicas de interpretação de imagens proporciona a criação de propostas de educação ambiental palpável e de fácil visualização ao cidadão, ou mesmo para os meios de comunicação (Correia, 2007). Este trabalho, em específico, utiliza técnicas de geoprocessamento para a predição de incêndios com base em diversos autores, tais como (Ribeiro et al, 2008 e Chuvieco et al, 2010) e a que aplica lógica fuzzy adaptada pelo presente autor.

Há diversos estudos para análise de risco de incêndios, no entanto, foram utilizadas poucas variáveis nos modelos preditivos, sem confiabilidade estatística e nenhuma análise de dependência espacial. Existem escassez de estudos de risco espacial de incêndios em escalas a nível municipal (1:100.000 ou maiores) envolvendo áreas urbanas. Um estudo de Alves e Cunha (2016), evidenciou as áreas de elevada suscetibilidade a riscos naturais na área urbana de Santa Clara (Coimbra/Portugal), entre elas os incêndios florestais, cujo método utilizado limitou-se em análises multicritério baseadas em fatores físicos do território.

Esse artigo pretende apresentar que o estudo de padrões espaciais de riscos de incêndios pode contribuir significativamente para com as ações de prevenção, trazendo uma nova visão sobre tais ações sendo possível avaliar e diagnosticar com clareza a classificação das áreas de risco.

\section{Modelos Aplicados e Testados nessa Pesquisa}

Nesta etapa serão relacionados os pesos e coeficientes pertinentes às metodologias utilizadas por Ribeiro et. al (2008), Chuvieco et. al (2010) e modelagem do próprio autor aplicando a lógica fuzzy. A escolha dessas metodologias ocorreu em função dos estudos serem recentes e amplamente citados na literatura, desenvolvidos na área de geração de mapas de risco de incêndio no Brasil e no exterior, respectivamente. Apesar desses estudos terem sido aplicados em área rural/florestal, adaptaram-se os métodos adotados para aplicação em área urbana.

Escolheu-se a modelagem por lógica fuzzy pelo fato das metodologias citadas anteriormente caracterizar e classificar as classes como limites rígidos entre elas. Porém a lógica fuzzy, possibilita trabalhar com valores que não têm limites rígidos definidos entre as classes. 


\subsection{Metodologia Proposta por Ribeiro et al, 2008}

Ribeiro et al (2008) baseia-se na avaliação multicritério, onde os fatores de análise devem ser representativos de acordo com as variáveis que poderão contribuir para o aumento do risco de incêndio, devendo ser independentes entre si. Após a escolha dos critérios representativos, estes são quantificados e qualificados de acordo com os seus atributos, onde cada atributo deve quantificar o desempenho de determinado critério de acordo com o objetivo, que neste caso é a determinação do potencial risco de incêndio numa determinada região. Os critérios selecionados são: ocupação do solo, rede viária, declividade, densidade demográfica e hidrografia. Obtém-se assim, a equação (1), podendo-se quantificar o risco em: Nulo, Baixo, Moderado, Alto, Muito Alto e Extremo. A Tabela 1 ilustra as classes de pesos de acordo com as potencialidades.

$$
R I S C O=U S+R V+D V+D D+H D
$$

Onde:

US: coeficiente de risco segundo o Uso do Solo; RV: coeficiente de risco segundo a Rede Viária; DV: coeficiente de risco segundo a Declividade; DD: coeficiente de risco segundo a Densidade Demográfica; HD: coeficiente de risco segundo a Hidrografia.

Tabela 1: Classes de risco de incêndios segundo metodologia proposta por Ribeiro (2008)

\begin{tabular}{c|c}
\hline Classes de Pesos & Classes de Riscos \\
\hline $0-3$ & Nulo \\
\hline $4-8$ & Baixo \\
\hline $9-12$ & Moderado \\
\hline $13-16$ & Alto \\
\hline $17-20$ & Muito Alto \\
\hline $21-22$ & Extremo \\
\hline
\end{tabular}

*Fonte: Ribeiro et. al (2008)

\subsection{Metodologia Proposta por Chuvieco et al, 2010}

Nesta segunda metodologia baseia-se na análise multicritério através da soma das ponderações das variáveis. Procede-se ao produto entre o peso e o respectivo coeficiente (critério). Soma-se os critérios, expresso pela equação 2, de modo que se quantifica o risco em: Muito Alto (0-30), Alto (31-60), Moderado (61-160), Baixo (161-190), Muito Baixo (191-230) e Nulo (231-255). Os pesos foram atribuídos a fim de dimensionar o mapa final entre 0 e 255 (Tabela 2). Embora seja uma escala arbitrária de pesos, leva-se em conta a importância relativa de cada variável como um fator de risco de incêndio.

$$
R I S C O=1+100 V+30 D+100 O E+5 E T+2 A L
$$

Em que:

$\mathrm{V}=$ coeficiente de risco da vegetação; $\mathrm{D}=$ coeficiente de risco da declividade; $\mathrm{OE}=$ coeficiente de risco da orientação das encostas; $\mathrm{ET}=$ coeficiente de risco da proximidade a estradas e trilhas; $\mathrm{AL}=$ coeficiente de risco da altitude. 
Tabela 2: Classes de risco de incêndios proposto por Chuvieco et. al (2010)

\begin{tabular}{c|c|c|c|c|c}
\hline $\begin{array}{c}\text { Classes de } \\
\text { Pesos }\end{array}$ & Riscos & $\begin{array}{c}\text { Classes de } \\
\text { Pesos }\end{array}$ & Riscos & $\begin{array}{c}\text { Classes de } \\
\text { Pesos }\end{array}$ & Riscos \\
\hline $0-30$ & Muito Alto & $61-160$ & Moderado & $191-230$ & Muito Baixo \\
\hline $31-60$ & Alto & $161-190$ & Baixo & $231-255$ & Nulo \\
\hline
\end{tabular}

*Fonte: Chuvieco et. al (2010).

\subsection{Metodologia Proposta com uso da Lógica Fuzzy}

Vários estudos de risco de incêndio são desenvolvidos em fórmulas determinísticas baseadas muitas vezes em fatores climáticos, porém a combinação entre esses fatores e a contribuição dos mesmos para o incêndio é fundamentada em observações e conhecimentos prévios de pesquisadores e está propensa a ter um maior grau de subjetividade (Silva e Pontes, 2011). Por isso, resolveu-se modelar a predição de risco de incêndio utilizando regras e variáveis linguísticas da lógica fuzzy (indicada por Burrough e Mcdonnell, 2005, na área de geoprocessamento e também por outros autores, tais como Barros e Bassanezi, 2006 e Silva et al, 2011) influenciado pela realidade local da área de estudo.

Para caracterizar formalmente um conjunto fuzzy, de acordo com Burrough e McDonnel (2005), pode-se recorrer ao conceito de pertinência, que é uma função onde dado o valor de um atributo $\mathrm{X}$, ela determina se o elemento avaliado pertence ou não a um determinado conjunto em análise. A definição de conjuntos fuzzy é dada de forma que um subconjunto A de um conjunto $\mathrm{U}$ é considerado subconjunto fuzzy de $\mathrm{U}$ se for descrito como um conjunto de pares ordenados segundo o que segue (SILVA et. al, 2011), na equação (3):

$$
A=\{(\mathrm{x}, \mu A(x)) ; x \grave{o} U \mu A(x) \grave{o}[0,1])\}
$$

Onde:

$\mu \mathrm{A}(\mathrm{x})$ é uma função de pertinência que determina com que grau x está em A:

$\mu \mathrm{A}(\mathrm{x})=1 \quad \mathrm{x}$ pertence totalmente ao conjunto $\mathrm{A}$;

$0<\mu \mathrm{A}(\mathrm{x})<1$ x pertence parcialmente ao conjunto $\mathrm{A}$;

$\mu \mathrm{A}(\mathrm{x})=0 \quad \mathrm{x}$ não pertence ao conjunto A.

Outro conceito essencial é o reconhecimento das variáveis em relação a existência do que consiste uma base de regras no relacionamento entre as mesmas. Isto se estabelece a partir do conhecimento do analista na forma de proposições do tipo "se E1 e/ou E2 então S1", onde E1 e E2 referem-se a classificações linguísticas das variáveis de entrada e S1 a de saída. Para Cecconello (2006), nas operações entre conjuntos fuzzy é comum utilizar as variáveis linguísticas, que podem ser qualitativas ou quantitativas, cujos valores assumidos são subconjuntos fuzzy. A variável linguística é um substantivo (qualitativo) e seus valores são adjetivos. Os conjuntos fuzzy representam os estados da variável que, em geral, são expressos por valores subjetivos como pequeno, muito, alto, etc.

A estrutura de um processo feito por um controlador fuzzy é mostrada na Figura 1, enfatizando-se seus componentes básicos: a interface de "fuzzyficação", a base de conhecimento, a base de dados, o procedimento de inferência e a interface de "defuzzyficação". 
Peixoto (2008) afirma que a interface de fuzzyficação toma os valores das variáveis de entrada, faz um escalonamento para condicioná-los aos universos de discurso normalizados e "fuzzyfica" os valores, transformando números em conjuntos fuzzy, de modo que possam se tornar instâncias de variáveis linguísticas.

Devem-se considerar ainda os modelos de controle fuzzy, a saber: a) Mamdani (Mamdani e Assilian, 1975, René, 1995). b) Larsen (Machado et al., 2006), c) Takagi-Sugeno (Takagi e Sugeno, 1985; Reyes, 2002), d) Tsukamoto (Machado et al, 2006).

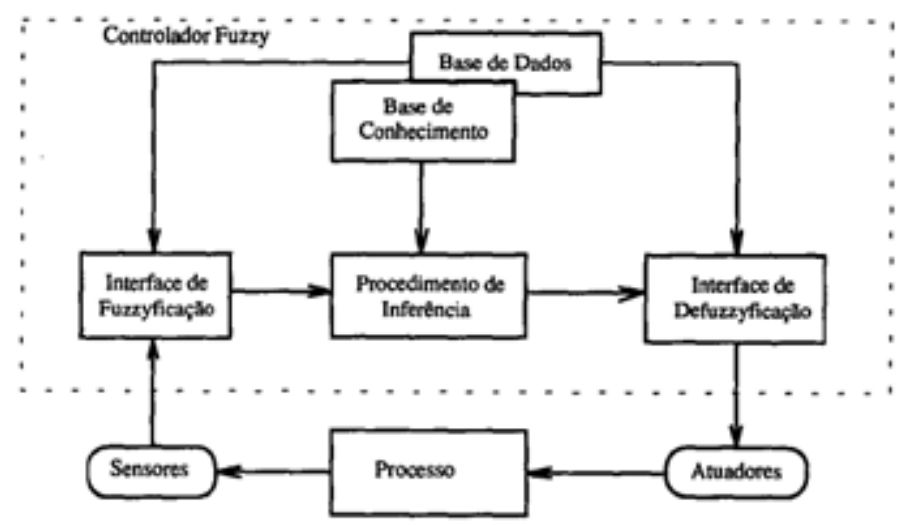

Figura 1: Estrutura Básica de um controlador Fuzzy Fonte: Gomide (1998) adaptado.

\subsection{Modelos de Precipitação Mensal}

A variável precipitação é de grande importância para analisar o risco de incêndio, tendo em vista que eleva a quantidade de umidade no solo e nos materiais combustíveis, dificultando ou impossibilitando o início e a propagação das chamas. As precipitações mensais inferiores a $25 \mathrm{~mm}$ recebem peso 3 (alto risco), conforme recomendações de Prudente (2010) e ilustrado na Tabela 3.

Tabela 3: Classes, risco e coeficientes de precipitação mensal

\begin{tabular}{c|c|c}
\hline $\begin{array}{c}\text { PRECIPITAÇÃO } \\
\text { MENSAL }\end{array}$ & RISCO & COEFICIENTE \\
\hline$<25 \mathrm{~mm}$ & Alto & 3 \\
\hline $25-75 \mathrm{~mm}$ & Moderado & 2 \\
\hline$>75 \mathrm{~mm}$ & Baixo & 1 \\
\hline
\end{tabular}

*Fonte: PRUDENTE (2010) Adaptado

\section{Metodologia}

A área de estudo correspondeu ao município de João Pessoa-PB e está localizado na porção leste do Estado, tendo como o ponto central as coordenadas $34^{\circ} 47^{\prime} 30$ "O e $07^{\circ} 09^{\prime} 28^{\prime \prime} \mathrm{S}$. 
Os dados utilizados foram disponibilizados no formato shapefile, projeção Lat/Long SIRGAS 2000 pela Secretaria da Segurança e da Defesa Social da Paraíba, integrado com o Corpo de Bombeiros Militar da Paraíba através do Centro Integrado de Operações, contendo a localização das ocorrências de incêndios, sítio do IBGE contendo informações da malha de setores censitários do município), sítio da AESA (Agência Executiva de Gestão das Águas do Estado da Paraíba) contendo a malha hidrográfica e estações pluviométricas e Prefeitura Municipal de João Pessoa (PMJP), contendo informações de bairros, rede viária, curvas de nível e vegetação do município. Os recursos de software utilizados nessa pesquisa foram: ArcGIS Desktop 10, MatLab 7.11 e Microsoft Excel.

A metodologia dos modelos de predição dos mapas de risco de incêndios segue o fluxograma (Figura 2), onde todas as etapas serão descritas a seguir.

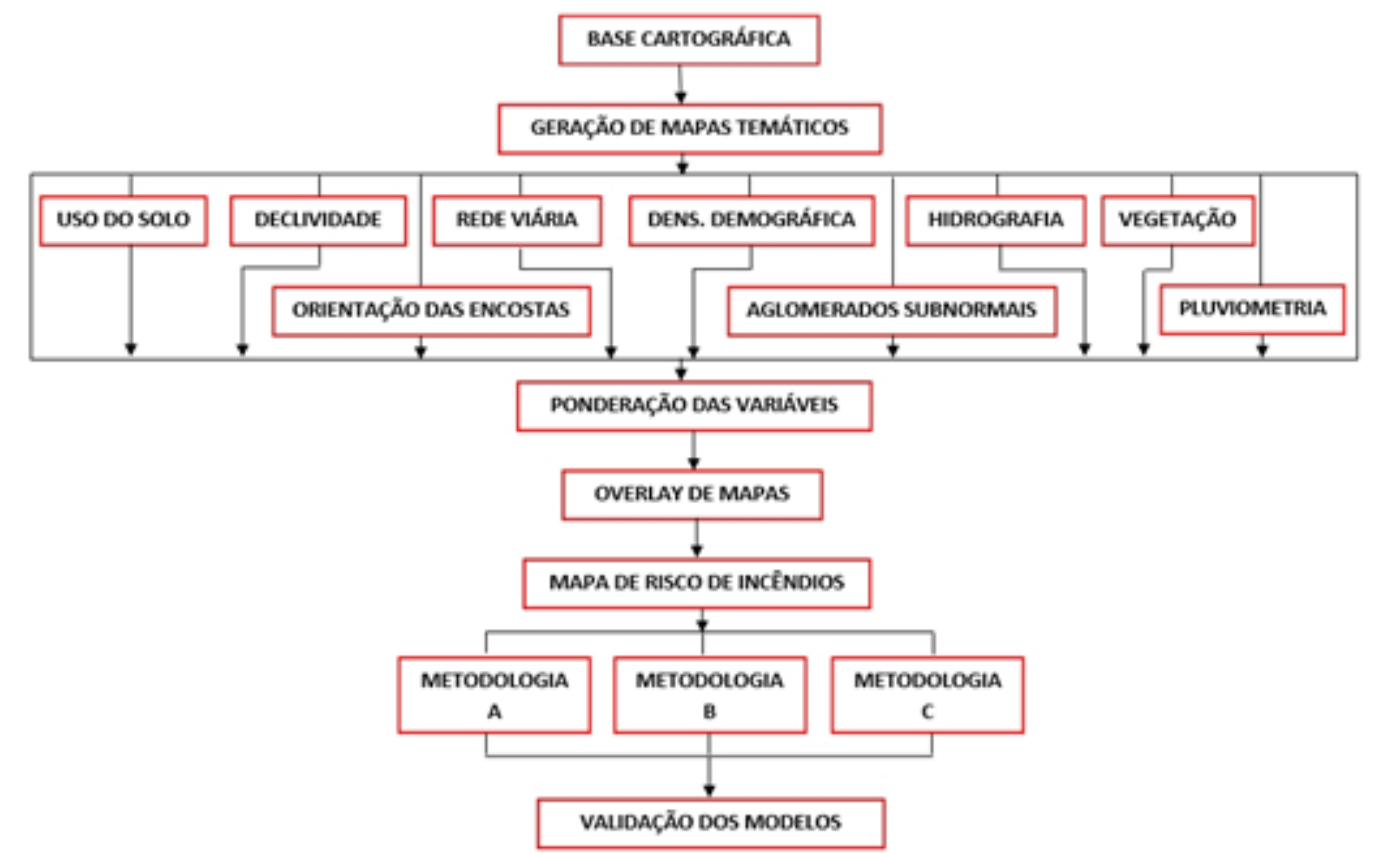

Figura 2: Fluxograma de execução geral da elaboração dos modelos de predição de riscos de incêndios

Tomando como ponto inicial a inserção e visualização da base cartográfica no SIG, realizou-se a identificação e separação das camadas correspondentes às variáveis utilizadas.

Para o mapa de uso do solo identificaram-se as áreas nas quais se apresentam as classes de uso e ocupação do solo na área de estudo, sendo atribuído o número de classes apresentadas no referencial teórico para a configuração de legenda do mapa.

O mapa de declividade foi gerado a partir da seleção das curvas de nível através de uma grade irregular que possibilitou a organização dos pontos de acordo com sua porcentagem de aclives e declives no terreno. Foram estabelecidas as classes de risco de incêndio propostas para essa variável, relacionando o grau de inclinação do terreno em função da sua influência na propagação do fogo.

Para o mapa temático da rede viária, baseou-se na proximidade a estradas, numa área de influência de $100 \mathrm{~m}$, sendo $50 \mathrm{~m}$ de raio para cada lado do eixo de logradouro. Após definição desse parâmetro foi gerado um buffer de $100 \mathrm{~m}$ de largura no SIG. Para gerar a área sem influência da rede viária, foi necessário extrair uma zona de interesse, que possibilitou limitar a região entre os layers do buffer e do limite municipal. Para essa análise, toda a área de estudo foi considerada como plana. 
O mapa temático da densidade demográfica foi gerado a partir da malha de setores censitários e os dados da população do Censo Demográfico 2010 do IBGE, onde foi calculado o número de habitantes por setor dividido pela sua área $\mathrm{em}^{\mathrm{km}^{2}}$.

O mapa de influência da hidrografia foi gerado considerando o raio de influência de 50m para todos os corpos de água presentes na área. No ambiente SIG, foi repetido o mesmo procedimento usado na geração do mapa de influência viária (buffer). As áreas dentro dos raios de influência foram consideradas com riscos, devido à maior proximidade aos corpos d'água, e as demais foram consideradas sem risco. Para essa análise, toda a área de estudo foi considerada como plana.

Foi atribuído o peso para o mapa temático de vegetação, conforme ilustrado anteriormente no referencial teórico.

Para a geração do mapa de orientação das encostas foi feito com base no mapa de declividade e classificado conforme a direção de ventos em três classes (sudeste, sudoeste e norte) e foram classificadas de acordo com as classes propostas no referencial teórico.

O mapa temático de pluviometria foi gerado a partir dos pontos das estações pluviométricas e posteriormente gerado as classes (Tabela 3) para os intervalos de precipitações pluviométricas. Foram gerados mapas das médias anual e mensal para o período de chuvas (abril a agosto), primeiro período de estiagem (janeiro a março) e segundo período de estiagem (setembro a dezembro).

A geração do mapa temático de aglomerados subnormais foi feito com base no arquivo shapefile gerado pelo IBGE em parceria com a PMJP referente ao ano de 2010, sobreposto com outras camadas de interesse, tais como malha viária, delimitação de bairros e limite municipal.

\subsection{Inferências da Metodologia com a Lógica Fuzzy}

Para Koproski et al (2008), cada área tem características próprias de risco e isto deve ser considerado no momento da escolha das variáveis para elaboração dos mapas de risco. É por esta razão que levou, na visão do autor dessa pesquisa, a elaborar uma metodologia utilizando a lógica fuzzy, levando em consideração as variáveis que influenciam fortemente para o risco de incêndio.

A descrição prática aplicada nesse trabalho consistiu em criar as regras fuzzy com a utilização do software MatLab. Apesar do ArcGIS possuir uma ferramenta de modelagem fuzzy, o autor preferiu a utilização do MatLab devido ao mesmo possuir um conhecimento técnico específico de uso e manipulação com essa ferramenta para fins de viabilização técnica e produção de resultados em um tempo mais reduzido.

A variável "Uso do Solo", avalia o peso da contribuição da cobertura vegetal predominante na região para o risco potencial de incêndio (Ribeiro et al 2008). Classificou-se as áreas cobertas por vegetação no perímetro urbano e a existência de recursos hídricos para a identificação de riscos. O grau de pertinência desse critério foi composto por quatro classes de risco. A função de pertinência utilizada foi a Linear decrescente e a Triangular que definiu os intervalos dentro dos quais a função de pertinência assume valores diferentes de zero, como também o ponto onde a função de pertinência é máxima (Tabela 4). 
Tabela 4: Valores de Pertinência dos números fuzzy para o Uso do Solo

\begin{tabular}{|c|c|c|c|c|c|}
\hline Uso do Solo & Risco & Função de Pertinência & \multicolumn{3}{|c|}{ Valores Fuzzy } \\
\hline & & & $\mu=0$ & $\mu=1$ & $\mu=0$ \\
\hline Hidrografia & Baixo & Linear Decrescente & - & 0 & 1 \\
\hline Vegetação & Moderado & Triangular & 0,8 & 1,5 & 2 \\
\hline Área Urbana & Alto & Triangular & 1,7 & 2,5 & 3 \\
\hline Parque & Muito Alto & Triangular & 2,7 & 3,5 & 4 \\
\hline
\end{tabular}

$\mathrm{Na}$ avaliação do efeito da precipitação, considerou-se não apenas a quantidade de chuvas, mas também sua distribuição estacional. Se a distribuição das chuvas em um local é uniforme durante todo o ano, sem uma estação seca definida, o potencial de ocorrência e propagação dos incêndios é menor do que um local onde a estação chuvosa está concentrada em alguns meses, com longos períodos de estiagem durante os outros meses. A distribuição da precipitação foi fator fundamental na definição do início, término e duração da estação de perigo do fogo (Soares, 1985). A função de pertinência foi a Linear decrescente e a Triangular. Os valores seguem na tabela 5 abaixo.

Tabela 5: Valores de Pertinência dos números fuzzy para a Pluviometria

\begin{tabular}{|c|c|c|c|c|}
\hline Risco & Função de Pertinência & \multicolumn{3}{|c|}{ Valores Fuzzy } \\
\hline & & $\mu=0$ & $\mu=1$ & $\mu=0$ \\
\hline Baixo & Linear Decrescente & - & 0 & 1 \\
\hline Moderado & Triangular & 0,8 & 1,5 & 2 \\
\hline Alto & Triangular & 1,7 & 2,5 & 3 \\
\hline
\end{tabular}

A rede viária permite visibilidade às pessoas que circulam nas vias, além do acesso às viaturas de combate e pode também funcionar como corta fogos. O acesso de pessoas e veículos aumenta o risco de incêndio (Ribeiro et al 2008). O grau de pertinência foi composto por duas classes. A função de pertinência utilizada foi a Linear decrescente e a Triangular (Tabela 6).

Tabela 6: Valores de Pertinência dos números fuzzy para a Rede Viária

\begin{tabular}{c|c|c|c|c}
\hline \multicolumn{2}{c|}{ Risco } & Função de Pertinência & \multicolumn{3}{c}{ Valores Fuzzy } \\
\hline Baixo & Linear Decrescente & $\mu=0$ & $\mu=1$ & $\mu=0$ \\
\hline Alto & Triangular & 0,8 & 0 & 1,6 \\
\hline
\end{tabular}

Para a declividade, conforme exposto por Ribeiro et al (2008), foi aplicado de modo adaptado à lógica fuzzy, onde a função de pertinência utilizada foi a Triangular (Tabela 7).

Tabela 7: Valores de Pertinência dos números fuzzy para a Declividade

\begin{tabular}{c|c|c|c|c}
\hline \multicolumn{2}{c|}{} & Função de Pertinência & \multicolumn{3}{|c}{ Valores Fuzzy } \\
\hline Baixo & Triangular & $\mu=0$ & $\mu=1$ & $\mu=0$ \\
\hline Moderado & Triangular & 0 & 7,5 & 15 \\
\hline Alto & Triangular & 2,5 & 24 & 40 \\
\hline
\end{tabular}

A definição da modelagem fuzzy para a densidade demográfica considerou o mesmo princípio teórico abordado por Ribeiro et al (2008). A função de pertinência foi a Triangular (Tabela 8).

Tabela 8: Valores de Pertinência dos números fuzzy para a Densidade Demográfica

\begin{tabular}{c|c|c|c|c}
\hline \multicolumn{2}{c|}{ Risco } & Função de Pertinência & \multicolumn{3}{|c}{ Valores Fuzzy } \\
\hline Baixo & Triangular & $\mu=0$ & $\mu=1$ & $\mu=0$ \\
\hline Moderado & Triangular & 0,8 & 0,5 & 1 \\
\hline Alto & Triangular & 1,8 & 2,4 & 2 \\
\hline
\end{tabular}


A hidrografia seguiu a mesma metodologia adotada por Ribeiro et al (2008) onde as áreas delimitadas pelos raios de influência foram consideradas como de risco, devido à maior proximidade aos corpos d'água, enquanto as demais são consideradas sem risco. A função de pertinência utilizada foi a Trapezoidal pela razão de os limites máximos determinaram o intervalo dentro do qual a função de pertinência é máxima e igual a 1. Os valores seguem na tabela 9 abaixo.

Tabela 9: Valores de Pertinência dos números fuzzy para a Hidrografia

\begin{tabular}{|c|c|c|c|c|}
\hline Risco & Função de Pertinência & \multicolumn{3}{|c|}{ Valores Fuzzy } \\
\hline & & $\mu=0$ & $\mu=1$ & $\mu=0$ \\
\hline Baixo & Trapezoidal & 0 & $0,4-0,6$ & 1 \\
\hline
\end{tabular}

A frequência de incêndios em comunidades gera preocupações e até suspeitas, não necessariamente fundamentadas. Inicialmente, no contexto mais apropriado das condições adversas e impróprias de localização dos aglomerados subnormais. O tempo seco favorece esses desastres porque as habitações são construídas com materiais de fácil combustão, como madeira e papelão, são geminadas, possuem ligações elétricas clandestinas com fios expostos, botijões de gás, fogões acesos, velas e fósforos ao alcance de crianças abandonadas na própria residência cujos responsáveis, frequentemente, estão ausentes em busca de recursos para sobrevivência e manutenção da família.

Para os aglomerados subnormais atribuiu-se risco alto para as áreas delimitadas por esta variável. Portanto, grau de pertinência desse critério foi composto por uma classe de risco apenas e função de pertinência utilizada foi a Linear Crescente pela razão de os limites máximos determinaram o intervalo dentro do qual a função de pertinência é máxima e igual a 1 (Tabela 10).

Tabela 10: Valores de Pertinência dos números fuzzy para os AGSN

\begin{tabular}{c|c|c|c|c}
\hline Risco & Função de Pertinência & \multicolumn{3}{|c}{ Valores Fuzzy } \\
\hline \multicolumn{2}{c}{} & $\mu=0$ & $\mu=1$ & $\mu=0$ \\
\hline Alto & Linear Crescente & 2 & 3 & 0 \\
\hline
\end{tabular}

\subsubsection{Modelagem para o Cálculo de Risco de Incêndio}

Cada grau de risco foi definido de acordo com o seu impacto sobre o aumento do risco de incêndio. Os pesos foram atribuídos na dimensão para o mapa final entre 0 e 25 levando em conta a importância relativa de cada variável como um fator de risco de incêndio.

A função de pertinência utilizada foi a Trapezoidal pela razão de que os limites máximos determinaram o intervalo dentro do qual a função de pertinência é máxima e igual a 1. Os valores adotados nessa função podem ser conferidos na tabela 11 abaixo.

Tabela 11: Valores de Pertinência dos números fuzzy para a o Cálculo Final do Risco de Incêndio

\begin{tabular}{c|c|c|c|c}
\hline \multicolumn{2}{c|}{ Risco } & Função de Pertinência & \multicolumn{3}{c}{ Valores Fuzzy } \\
\hline \multicolumn{2}{|c|}{} & $\mu=0$ & $\mu=1$ & $\mu=0$ \\
\hline Nulo & Triangular & - & 0 & 3 \\
\hline Baixo & Triangular & 1,5 & 5 & 8 \\
\hline Moderado & Triangular & 6 & 9 & 12 \\
\hline Alto & Triangular & 10,5 & 13 & 16 \\
\hline Muito Alto & Triangular & 14,5 & 16 & 20 \\
\hline Extremo & Triangular & 18,5 & 21 & 29 \\
\hline
\end{tabular}


A definição das classes de risco baseou-se em dados qualitativos e quantitativos. Com isso, a construção dos valores de pertinência da tabela acima foi definida com base na tabela de risco proposta por Ribeiro et al (2008) e posterior aplicação de regras e modelagem do cálculo do valor fuzzy estabelecido pelo modelo Mamdani-Larsen.

\subsubsection{Construção das Regras}

As regras foram definidas de acordo com o grau de vulnerabilidade das variáveis utilizadas para essa modelagem, de modo que o valor final resultasse no fator de risco também definido pelas variáveis linguísticas: Nulo, Baixo, Moderado, Alto, Muito Alto e Extremo. Foram criadas, no total, 406 regras e para essa definição foi utilizado o modelo Mamdani-Larsen por se utilizar mais de uma variável linguística e através do operador booleano $A N D$ foi efetuado o produto dessas variáveis, por exemplo: SE (Declividade é baixa) E (Uso do Solo é baixo) E (Densidade Demográfica é baixa) E (Hidrografia é baixa) E (AGSN é baixo) E (Pluviometria é alta) E (Rede Viária é baixa) ENTÃO (Risco é Nulo).

Após a elaboração das regras que definiram as classes de risco de incêndio, o banco de dados contendo os atributos no ArcGIS foi exportado em formato *.xls com os valores definidos nessa modelagem. Esses valores foram inseridos no MatLab e o valor fuzzy calculado foi inserido nesse mesmo banco de dados e importado novamente para o ArcGIS através da junção das tabelas, possibilitando assim, a geração do mapa de risco.

Após a geração dos mapas temáticos, foi realizado o processo de ponderação das variáveis no banco de dados que compõe os mapas, sendo que a etapa seguinte correspondeu à sobreposição dos mesmos para a geração do mapa de risco. Foi utilizada a análise espacial de sobreposição (overlay), levando em conta os atributos das variáveis envolvidas, sendo adicionada uma coluna no banco de dados final da sobreposição, que corresponde ao somatório de influência de cada componente utilizado no processo. Através de consultas ao banco de dados, foi possível classificar os níveis de informação pelo peso de risco na área de estudo e gerar o mapa de riscos de incêndios.

\section{Resultados e Discussão}

Os resultados obtidos são visualizados através dos mapas, sendo possível a avaliar os modelos de predição de risco de incêndio, que são analisados e discutidos a seguir.

Com a finalidade de analisar a confiabilidade dos mapas de risco de incêndio, foram realizadas análises com respeito aos dados de ocorrências de incêndios registrados e atendidos pelo Corpo de Bombeiros no ano de 2010 e com a distribuição espacial dos mesmos, onde foram registradas 462 ocorrências no ano em questão (Figura 3). 


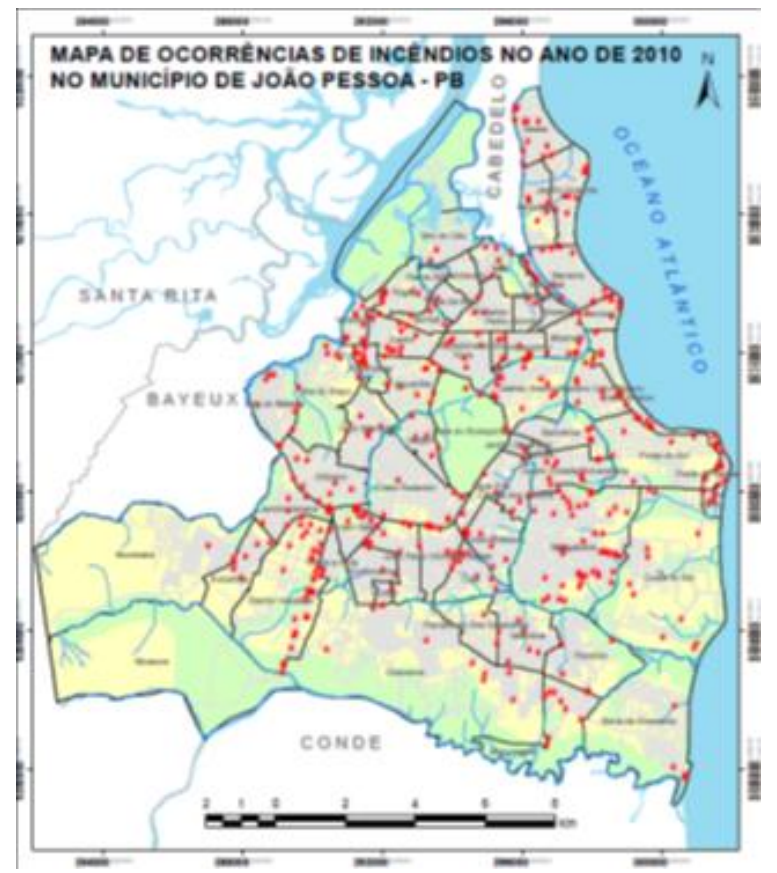

Figura 3: Mapa dos pontos de ocorrências de incêndios atendidas pelo Corpo de Bombeiros no ano de 2010

\subsection{Avaliação da Metodologia proposta por Ribeiro et al, (2008)}

A partir da comparação entre o mapa de risco de incêndio gerado com base na metodologia de Ribeiro et al (2008) e os pontos de incêndios, constataram-se os seguintes resultados ilustrados na Tabela 12 a seguir.

Tabela 12: Relação da classe de risco com as ocorrências de incêndios (Ribeiro et al, 2008)

\begin{tabular}{c|c|c|c|c}
\hline RISCO & $\begin{array}{c}\mathbf{N}^{\mathbf{0}} \mathbf{D E} \\
\text { OCORRÊECIAS }\end{array}$ & \% TOTAL & $\begin{array}{c}\text { ÁREA } \\
\mathbf{( k m}^{\mathbf{2}}\end{array}$ & $\begin{array}{c}\text { PONTOS POR } \\
\mathbf{k m}^{\mathbf{2}}\end{array}$ \\
\hline Nulo & 4 & $1 \%$ & 14,333 & 0,28 \\
\hline Baixo & 163 & $35 \%$ & 110,87 & 1,47 \\
\hline Moderado & 263 & $57 \%$ & 82,35 & 3,19 \\
\hline Alto & 32 & $7 \%$ & 6,5 & 4,92 \\
\hline
\end{tabular}

Observa-se que o perfil de risco se compatibilizou com as ocorrências de incêndios, onde a maioria delas ocorreram em áreas de risco moderado. A princípio conclui-se que essa modelagem não é confiável tendo em vista que a maioria dos pontos deveriam estar em áreas de risco alto. Observase que a densidade de pontos concentrou-se em áreas de risco alto com uma concentração de 4,92 ocorrências $/ \mathrm{km}^{2}$. Considerar apenas a densidade de pontos não valida o modelo, pois não há uma separação entre as magnitudes e as classes de incêndios, nas áreas dos incêndios e nem os prejuízos materiais.

Outra análise aplicou o coeficiente de determinação $\left(R^{2}\right)$ de 0,7259 , ou seja, $72,59 \%$ da variação espacial é explicada pelo modelo proposto.

O índice Global de Moran teve valor de 0,662532 com significância de 0,01, indicando que há forte autocorrelação espacial. Pode-se observar que o mapa temático relativo ao risco de incêndio 
de acordo com Ribeiro et. al (2008), mostra claramente um padrão espacial. Desta forma, áreas que apresentam um determinado fator de risco similar, de uma maneira geral, estão mais próximas umas das outras no mapa apresentado.

No mapa LISA (Figura 4), identifica-se o agrupamento de objetos espaciais com valores de atributos semelhantes onde somente os objetos para os quais os valores do índice local de Moran que foram considerados significantes $(p$-value < 0,05$)$ são destacados (representados pela cor verde e vermelha), o que corresponde a $48 \%$ da área municipal com autocorrelação espacial, acarretando em $52 \%$ da área territorial (representado pela cor cinza) com significância abaixo de 95\%, sendo considerado como não significantes, ou seja, não há autocorrelação espacial.
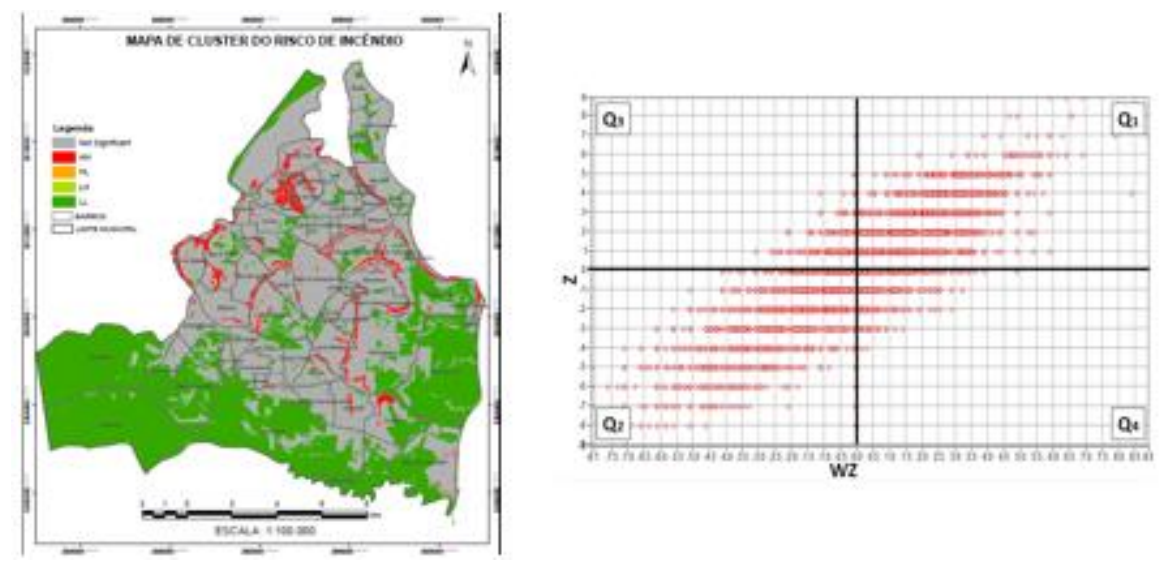

Figura 4: Clusters do Risco de Incêndio e Diagrama de Espalhamento de Moran para o modelo proposto por Ribeiro et al (2008)

Percebe-se no mapa de cluster que as regiões destacadas na cor vermelha possuem valores autocorrelacionados com alto risco de incêndio. As áreas classificadas na cor verde se autocorrelacionam com baixos padrões de risco de incêndio e o diagrama de espalhamento de Moran para o mapa temático mostra a distribuição da variabilidade da dependência espacial para as classes de risco de incêndio.

\subsection{Validação da Metodologia proposta por Chuvieco et al, (2010)}

Comparando-se o mapa de risco gerado com base na metodologia de Chuvieco et. al (2010) e as ocorrências de incêndios, observaram-se os seguintes resultados ilustrados na Tabela 13 a seguir.

Tabela 13: Relação da classe de risco com as ocorrências de incêndios (Chuvieco et al, 2010)

\begin{tabular}{c|c|c|c|c}
\hline RISCO & $\begin{array}{c}\mathbf{N}^{\mathbf{0}} \mathbf{D E} \\
\text { OCORRÊNCIAS }\end{array}$ & \% TOTAL & $\begin{array}{c}\text { ÁREA } \\
\left(\mathbf{k m}^{\mathbf{2}}\right.\end{array}$ & PONTOS/km \\
\hline Muito Baixo & 94 & $20 \%$ & 57,79 & 1,62 \\
\hline Baixo & 177 & $38 \%$ & 87,76 & 2,01 \\
\hline Moderado & 191 & $41 \%$ & 68,5 & 2,79 \\
\hline
\end{tabular}

De acordo com a tabela, a maioria dos incêndios ocorreram em áreas de risco moderado, totalizando $41 \%$ das ocorrências. Analisando a relação da densidade de pontos, as ocorrências se concentraram em áreas classificadas como risco moderado apresentando uma concentração de 2,79 ocorrências $/ \mathrm{km}^{2}$.

O $R^{2}$ foi de 0,21600 , ou seja, $21,60 \%$ da variação espacial é explicada pelo modelo proposto. 
O valor do índice de Moran para o mapa de risco de incêndio proposto por Chuvieco et al (2010) foi de 0,480379 . O que indica uma moderada dependência espacial se comparado com o índice de Moran calculado para o mapa de risco proposto por Ribeiro et al (2008). Mesmo assim, como o índice de Moran apresentou valor positivo, o modelo proposto apresenta autocorrelação espacial. O valor de significância estatística para o íncide foi de 0,01 . Portanto, a hipótese nula é rejeitada.

No mapa LISA (Figura 5), identifica-se clusters espaciais (representados pela cor verde e vermelha) correspondendo a 35\% do município. 56\% da área territorial (representado pela cor cinza) foi considerado como não significantes. Foi detectada no mapa a presença de outliers (representado pelas cores laranja e amarelo), ocupando apenas 9\% da área municipal. Há necessidade de analisar se as áreas classificadas como "LH", ou seja, baixos valores circundados de altos valores são casos isolados de risco em potencial ou se realmente são valores que estão totalmente fora do padrão de autocorrelação ratificado pelo diagrama de espalhamento de Moran.
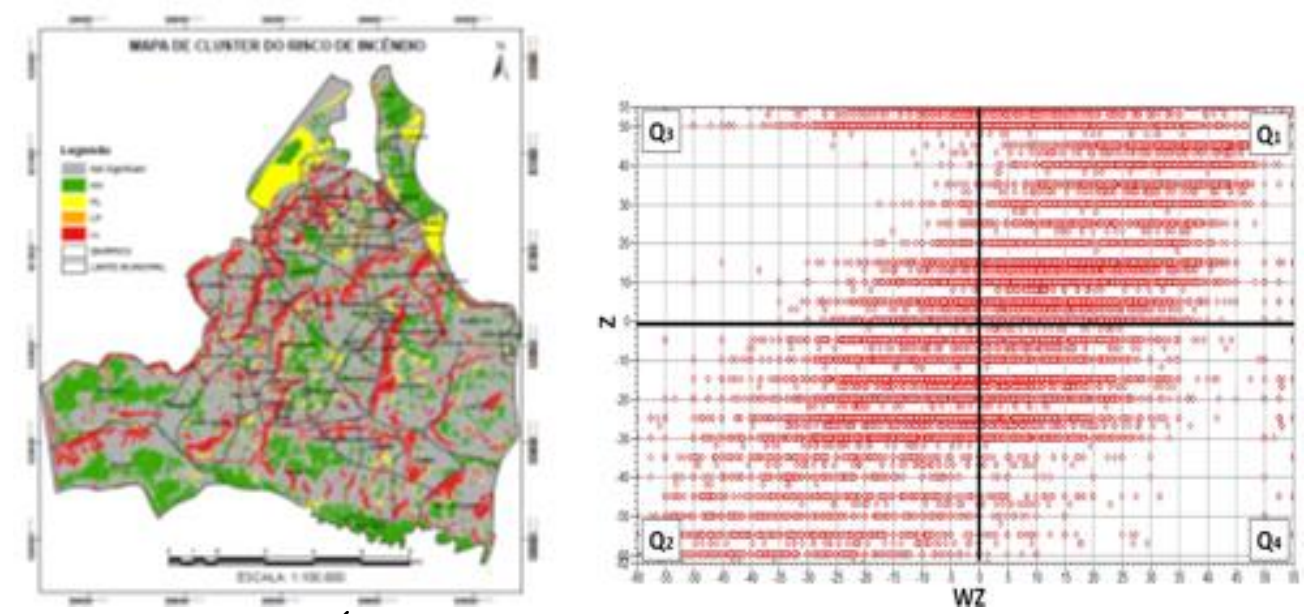

Figura 5: Mapa de Índice Local de Moran e o Diagrama de Espalhamento de Moran para o mapa de risco de incêndio proposto por Chuvieco et. al (2010)

\subsection{Avaliação da Metodologia da Lógica Fuzzy}

Observando os mapas de risco de incêndio gerados de acordo com a lógica fuzzy e em contraponto com as ocorrências reais de incêndios, considerando o mapa temático de risco de incêndio relacionado com a pluviometria anual média, chegou-se aos seguintes resultados ilustrados na Tabela 10.

Tabela 14: Relação da classe de risco com as ocorrências de incêndios (Fuzzy Pluviometria

\begin{tabular}{c|c|c|c|c}
\hline \multicolumn{5}{|c}{ Anual) } \\
\hline \multirow{2}{*}{ RISCO } & $\begin{array}{c}\mathbf{N}^{\mathbf{0}} \mathbf{D E} \\
\text { OCORRENCIAS }\end{array}$ & $\begin{array}{c}\text { \% } \\
\text { TOTAL }\end{array}$ & $\begin{array}{c}\text { ÁREA } \\
\left(\mathbf{k m}^{2}\right)\end{array}$ & PONTOS/ÁREA \\
\hline Nulo & 7 & $2 \%$ & 23,48 & 0,30 \\
\hline Muito Baixo & 131 & $28 \%$ & 84,89 & 1,54 \\
\hline Baixo & 127 & $27 \%$ & 38,87 & 3,27 \\
\hline Moderado & 105 & $23 \%$ & 34,05 & 3,08 \\
\hline Alto & 92 & $20 \%$ & 28,72 & 3,20 \\
\hline
\end{tabular}


Nessa modelagem, a maior parte dos incêndios ocorreram em áreas de risco muito baixo, representando $28 \%$ das ocorrências. A relação da densidade de pontos por $\mathrm{km}^{2}$, concentraram-se em áreas classificadas como risco baixo, com uma concentração de 3,27 ocorrências $/ \mathrm{km}^{2}$.

O $R^{2}$ foi de 0,9383 , ou seja, $93,83 \%$ da variação espacial é explicada pelo modelo proposto.

O índice de Moran obteve valor de 0,742717 com significância de 0,01. Valor esse que confirma a rejeição da hipótese nula. Observa-se que o mapa temático relativo ao risco de incêndio gerado com base na lógica fuzzy para o ano em questão mostra autocorrelação espacial. As áreas que apresentam um determinado fator de risco semelhante, de uma maneira geral, estão mais dependentes espacialmente umas das outras no mapa apresentado.

Para o mapa LISA (Figura 6), a cor verde e vermelha corresponde a $41 \%$ da área municipal com autocorrelação espacial e 59\% da área territorial (cor cinza) com significância abaixo de $95 \%$.
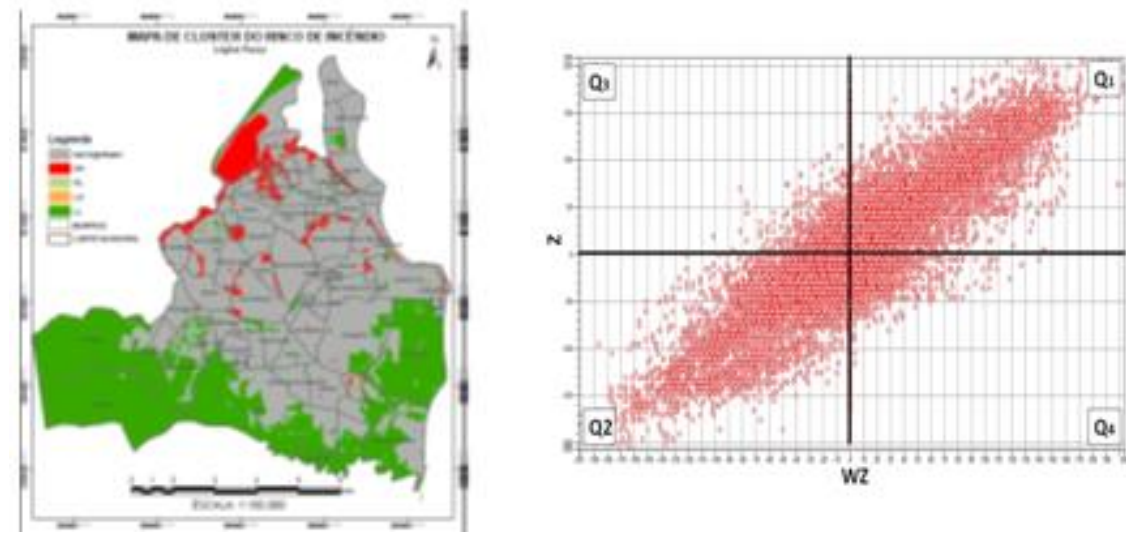

Figura 6: Mapa de Cluster do Risco de Incêndio e Diagrama de Espelhamento de Moran para o ano de 2010 com base na lógica fuzzy

Percebe-se no mapa de cluster que as regiões destacadas em vermelho possuem valores autocorrelacionados com alto risco de incêndio. As áreas em verde se autocorrelacionam com baixos padrões de risco de incêndio. O Diagrama de Espalhamento de Moran mostra a distribuição da variabilidade da dependência espacial para as classes de risco de incêndio.

O segundo mapa de risco de incêndio para o período chuvoso gerado com base na lógica fuzzy e as ocorrências de incêndios no mesmo período apresentou os seguintes resultados ilustrados na Tabela 15 a seguir.

Tabela 15: Relação da classe de risco com as ocorrências de incêndios (Fuzzy Período Chuvoso)

\begin{tabular}{c|c|c|c|c}
\hline \multirow{2}{*}{ RISCO } & $\begin{array}{c}\mathbf{N}^{\mathbf{0}} \mathbf{D E} \\
\text { OCORRENCIAS }\end{array}$ & $\begin{array}{c}\text { \% } \\
\text { TOTAL }\end{array}$ & $\begin{array}{c}\text { ÁREA } \\
\left(\mathbf{k m}^{2}\right)\end{array}$ & PONTOS/AREA \\
\hline Nulo & 1 & $1 \%$ & 28,95 & 0,03 \\
\hline Muito Baixo & 20 & $18 \%$ & 64,20 & 0,31 \\
\hline Baixo & 50 & $44 \%$ & 65,12 & 0,77 \\
\hline Moderado & 21 & $18 \%$ & 23,89 & 0,88 \\
\hline Alto & 22 & $19 \%$ & 27,35 & 0,80 \\
\hline
\end{tabular}

Constatou-se que a maioria dos eventos ocorreram em áreas de risco baixo, representando $44 \%$ das ocorrências. A relação da densidade de pontos $/ \mathrm{km}^{2}$ demonstrou que os incêndios concentraram-se em áreas classificadas como risco moderado com 0,88 ocorrências $/ \mathrm{km}^{2}$.

O valor do $R^{2}$ foi de 0,9919 , ou seja, $99,19 \%$ da variação espacial é explicada pelo modelo proposto. Considerando o valor de alfa igual a 0,05.

O valor do índice de Moran para o mapa de risco de incêndio no período chuvoso foi de 0,747741 . O que indica uma dependência espacial forte com significância de 0,01 . 
No mapa LISA (Figura 7), a cor verde e vermelha corresponde a $63 \%$ do município com existência de autocorrelação espacial e $57 \%$ da área territorial (cor cinza) sendo considerado como não significantes ratificado através do diagrama de espalhamento de Moran.
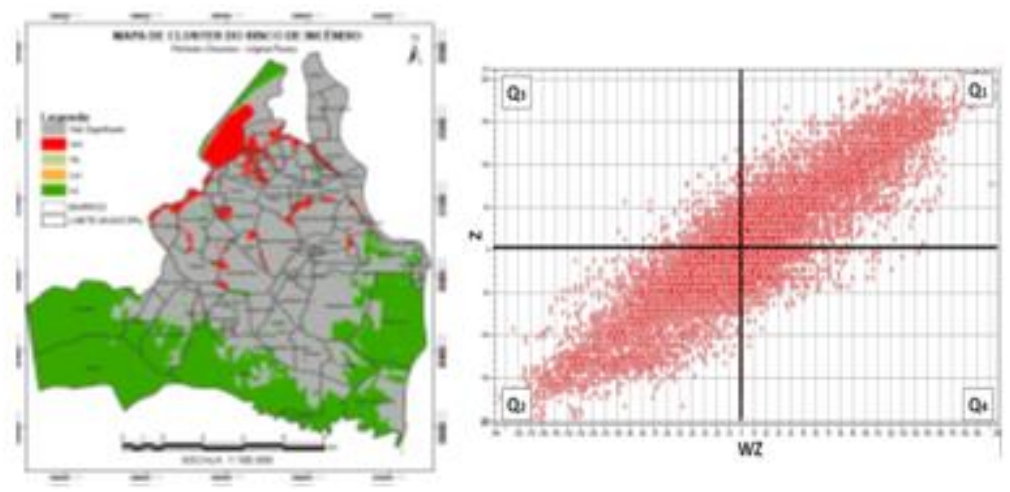

Figura 7: Mapa LISA e Diagrama de Espalhamento de Moran para o mapa de risco no período chuvoso

$\mathrm{O}$ terceiro mapa gerado de risco de incêndio para o primeiro período de estiagem com base na lógica fuzzy e as ocorrências de incêndios registradas no mesmo período apresentou os seguintes resultados ilustrados na Tabela 16 apresentados a seguir.

Tabela 16: Relação da classe de risco com as ocorrências de incêndios (Fuzzy $1^{\circ}$ Período de Estiagem)

\begin{tabular}{c|c|c|c|c}
\hline \multirow{2}{*}{ RISCO } & $\begin{array}{c}\mathbf{N}^{\mathbf{0}} \mathbf{D E} \\
\text { OCORRENCIAS }\end{array}$ & $\begin{array}{c}\boldsymbol{\%} \\
\text { TOTAL }\end{array}$ & $\begin{array}{c}\text { ÁREA } \\
\mathbf{( k m}^{\mathbf{2}}\end{array}$ & PONTOS/ÁREA \\
\hline Nulo & 2 & $2 \%$ & 26,28 & 0,08 \\
\hline Muito Baixo & 18 & $14 \%$ & 66,39 & 0,27 \\
\hline Baixo & 56 & $43 \%$ & 61,17 & 0,92 \\
\hline Moderado & 21 & $16 \%$ & 26,89 & 0,78 \\
\hline Alto & 32 & $25 \%$ & 29,03 & 1,10 \\
\hline
\end{tabular}

Constatou-se no mapa para o primeiro período de estiagem que grande parte dos incêndios registrados no período ocorreram em áreas de risco baixo, representando $43 \%$ das ocorrências. A densidade mostrou que os incêndios ocorreram em áreas de risco alto com 1,10 ocorrências $/ \mathrm{km}^{2}$.

O $R^{2}$ foi de 0,8663 , ou seja, $86,63 \%$ da variação espacial é explicada pelo modelo proposto e o índice global de Moran teve valor de 0,755966 com significância de 0,01. No mapa LISA (Figura 8), a cor verde e vermelha corresponde a $43 \%$ da área municipal com autocorrelação espacial e $57 \%$ da área territorial (cor cinza) não há autocorrelação espacial.
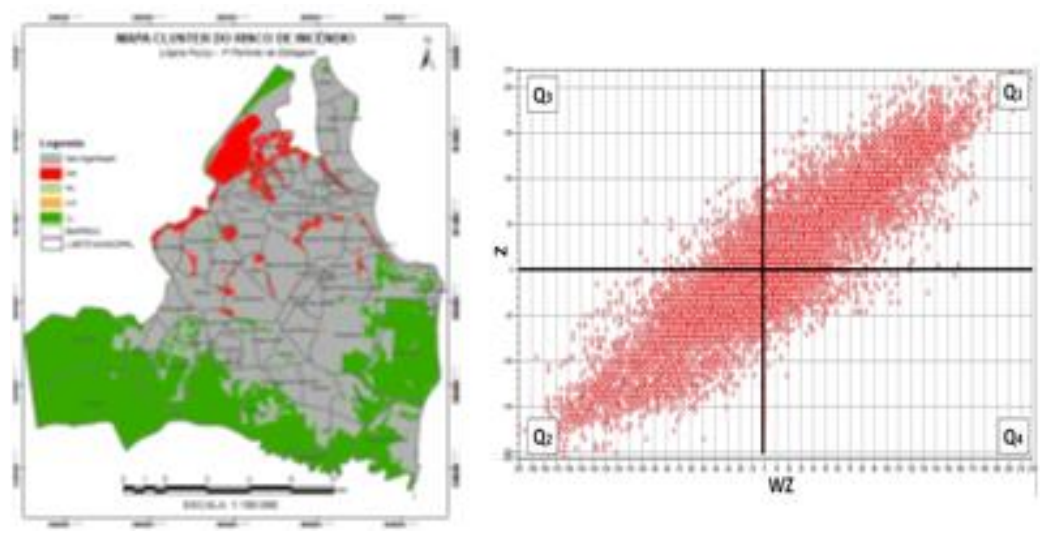

Figura 8: Mapa Cluster e Diagrama de Espalhamento de Moran do Risco de Incêndio $1^{\circ}$ período de estiagem 
Percebe-se ainda no mapa de cluster que as regiões destacadas em vermelho possuem valores autocorrelacionados com alto risco de incêndio e as classificadas na cor verde com baixos padrões de risco, ratificado pelo Diagrama de Espalhamento de Moran.

O quarto e último mapa apresentado refere-se ao risco de incêndio para o segundo período de estiagem gerado com base na lógica fuzzy e as ocorrências de incêndios registradas no mesmo período apresentando os seguintes resultados ilustrados na Tabela 17 a seguir.

Tabela 17: Relação da classe de risco com as ocorrências de incêndios (Fuzzy $2^{\circ}$ Período

\begin{tabular}{c|c|c|c|c}
\multicolumn{5}{|c}{ de Estiagem) } \\
\hline RISCO & $\begin{array}{c}\mathbf{N}^{\mathbf{0}} \mathbf{D E} \\
\text { OCORRENCIAS }\end{array}$ & $\begin{array}{c}\mathbf{\%} \\
\text { TOTAL }\end{array}$ & $\begin{array}{c}\text { ÁREA } \\
\left(\mathbf{k m}^{2}\right)\end{array}$ & PONTOS/ÁREA \\
\hline Nulo & 3 & $1 \%$ & 16,27 & 0,18 \\
\hline Muito Baixo & 28 & $13 \%$ & 60,45 & 0,46 \\
\hline Baixo & 60 & $27 \%$ & 44,69 & 1,34 \\
\hline Moderado & 87 & $40 \%$ & 54,72 & 1,59 \\
\hline Alto & 42 & $19 \%$ & 33,36 & 1,26 \\
\hline
\end{tabular}

De acordo com a Tabela 17, a maioria dos incêndios ocorreram em áreas de risco moderado e também na relação da densidade de pontos $/ \mathrm{km}^{2}$, com uma concentração de 1,59 ocorrências $/ \mathrm{km}^{2}$.

O $R^{2}$ foi de 0,9672 , ou seja, $96,72 \%$ da variação espacial é explicada pelo modelo proposto.

O índice de Moran para o mapa de risco de incêndio no período chuvoso foi de 0,747065 . O que indica uma ampla dependência espacial com significância estatística de 0,01 .

No mapa LISA (Figura 9), a cor verde e vermelha corresponde a 42\% do município com existência de autocorrelação espacial e 58\% da área territorial (cor cinza) são não significantes, ratificado pelo diagrama de espalhamento de Moran.

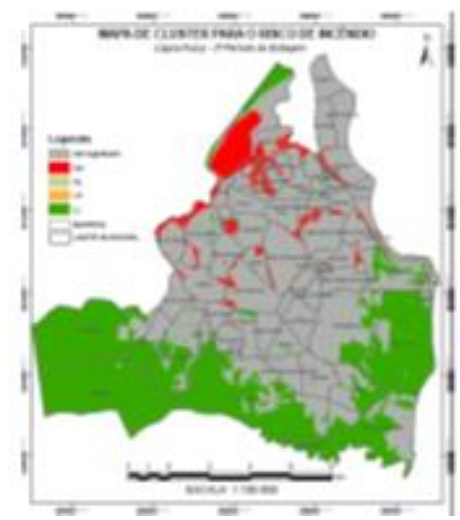

Figura 9: Mapa LISA e Diagrama de Espalhamento de Moran para o mapa de risco $2^{\circ}$ período de estiagem

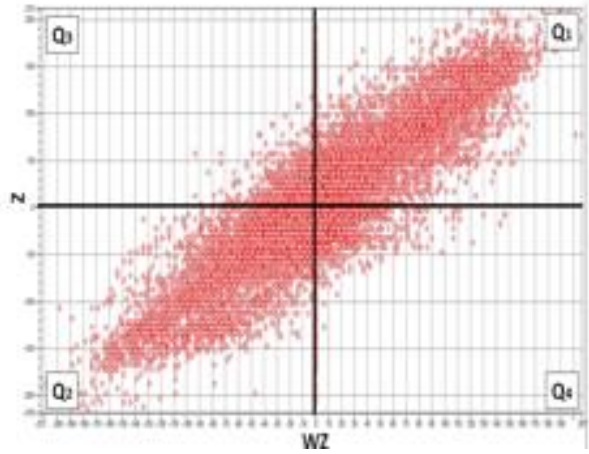

\subsection{Análise Comparativa entre as metodologias}

As Tabelas 18, 19, 20 e 21 resumem os modelos apresentados com os valores da classificação do risco na área de estudo, comparando a relação entre a densidade de ocorrências de incêndios $/ \mathrm{km}^{2}$, a classificação das áreas de risco e os valores do índice global de Moran, $p$-value e $\mathrm{R}^{2}$. 
Tabela 18: Comparativo entre os modelos apresentados de acordo com o percentual de ocupação

\begin{tabular}{|c|c|c|c|c|c|}
\hline METODOLOGIA & $\begin{array}{l}\text { RISCO } \\
\text { NULO }\end{array}$ & $\begin{array}{l}\text { RISCO } \\
\text { MUITO } \\
\text { BAIXO }\end{array}$ & $\begin{array}{l}\text { RISCO } \\
\text { BAIXO }\end{array}$ & $\begin{array}{c}\text { RISCO } \\
\text { MODERADO }\end{array}$ & $\begin{array}{l}\text { RISCO } \\
\text { ALTO }\end{array}$ \\
\hline Ribeiro et al (2008) & $1 \%$ & - & $35 \%$ & $57 \%$ & $7 \%$ \\
\hline Chuvieco et al (2010) & - & $20 \%$ & $38 \%$ & $41 \%$ & - \\
\hline Fuzzy (Anual) & $2 \%$ & $28 \%$ & $27 \%$ & $23 \%$ & $20 \%$ \\
\hline Fuzzy (Per. Chuvoso) & $1 \%$ & $18 \%$ & $44 \%$ & $18 \%$ & $19 \%$ \\
\hline Fuzzy $\left(1^{\mathrm{a}}\right.$ Estiagem $)$ & $2 \%$ & $14 \%$ & $43 \%$ & $16 \%$ & $25 \%$ \\
\hline Fuzzy (2 $2^{\text {a }}$ Estiagem $)$ & $1 \%$ & $13 \%$ & $27 \%$ & $40 \%$ & $19 \%$ \\
\hline
\end{tabular}

Tabela 19: Comparativo da densidade de pontos $/ \mathrm{km}^{2}$ e classificação das áreas de risco

\begin{tabular}{c|c|c|c|c|c}
\hline METODOLOGIA & $\begin{array}{c}\text { RISCO } \\
\text { NULO }\end{array}$ & $\begin{array}{c}\text { RISCO } \\
\text { MUITO } \\
\text { BAIXO }\end{array}$ & $\begin{array}{c}\text { RISCO } \\
\text { BAIXO }\end{array}$ & $\begin{array}{c}\text { RISCO } \\
\text { MODERADO }\end{array}$ & $\begin{array}{c}\text { RISCO } \\
\text { ALTO }\end{array}$ \\
\hline Ribeiro et al $(2008)$ & 0,28 & - & 1,47 & 3,19 & 4,92 \\
\hline Chuvieco et al $(2010)$ & - & 1,63 & 2,02 & 2,79 & - \\
\hline Fuzzy (Anual) & 0,30 & 1,54 & 3,27 & 3,08 & 3,20 \\
\hline $\begin{array}{c}\text { Fuzzy (Período } \\
\text { Chuvoso) }\end{array}$ & 0,03 & 0,31 & 0,77 & 0,88 & 0,80 \\
\hline Fuzzy (1 ${ }^{\circ}$ Período Est.) & 0,08 & 0,27 & 0,92 & 0,78 & 1,10 \\
\hline Fuzzy (2 ${ }^{\circ}$ Período Est.) & 0,18 & 0,46 & 1,34 & 1,59 & 1,26 \\
\hline
\end{tabular}

Tabela 20: Cálculo da frequência da densidade de pontos $/ \mathrm{km}^{2}$ e classificação das áreas de risco

\begin{tabular}{c|c|c|c|c|c}
\hline METODOLOGIA & $\begin{array}{c}\text { RISCO } \\
\text { NULO }\end{array}$ & $\begin{array}{c}\text { RISCO } \\
\text { MUITO } \\
\text { BAIXO }\end{array}$ & $\begin{array}{l}\text { RISCO } \\
\text { BAIXO }\end{array}$ & $\begin{array}{c}\text { RISCO } \\
\text { MODERADO }\end{array}$ & $\begin{array}{c}\text { RISCO } \\
\text { ALTO }\end{array}$ \\
\hline Ribeiro (2008) & 0,22 & - & 2,51 & 3,16 & 2,90 \\
\hline Chuvieco et al (2010) & - & 0,70 & 1,63 & 2,06 & - \\
\hline Fuzzy (Anual) & 0,26 & 1,25 & 2,90 & 3,65 & 3,34 \\
\hline Fuzzy (Período Chuvoso) & 0,06 & 0,31 & 0,71 & 0,90 & 0,82 \\
\hline Fuzzy (1 $1^{\circ}$ Período Estiagem) & 0,07 & 0,34 & 0,80 & 1,01 & 0,92 \\
\hline Fuzzy (2 $2^{\text {Período Estiagem) }}$ & 0,11 & 0,53 & 1,23 & 1,55 & 1,42 \\
\hline
\end{tabular}

Tabela 21: Cálculos do Índice Global de Moran, p-valor e $\mathrm{R}^{2}$ para os modelos apresentados

\begin{tabular}{c|c|c|c}
\hline METODOLOGIA & $\begin{array}{c}\text { ÍNDICE } \\
\text { GLOBAL DE } \\
\text { MORAN }\end{array}$ & $\boldsymbol{p}$-value & $\mathbf{R}^{\mathbf{2}}$ \\
\hline Ribeiro (2008) & 0,66532 & 0,01 & 0,725964408 \\
\hline Chuvieco et al (2010) & 0,480379 & 0,01 & 0,216005095 \\
\hline Fuzzy (Anual) & 0,742717 & 0,01 & 0,938394256 \\
\hline $\begin{array}{c}\text { Fuzzy (Período } \\
\text { Chuvoso) }\end{array}$ & 0,747741 & 0,01 & 0,991974981 \\
\hline Fuzzy (1 ${ }^{\mathbf{o}}$ Período Est.) & 0,755966 & 0,01 & 0,866397594 \\
\hline Fuzzy (2 ${ }^{\text {Período Est.) }}$ & 0,747065 & 0,01 & 0,967266107 \\
\hline
\end{tabular}

Todos os modelos apresentaram algumas áreas em comum de destaque no município. Entre elas, pode-se citar a região do bairro São José, Área de Preservação Permanente na divisa dos bairros Cabo Branco e Altiplano Cabo Branco, Comunidade São Rafael às margens da rodovia BR-230, comunidades do Baleado, Boa Esperança e Bom Samaritano ao longo do curso do rio Jaguaribe divisa dos bairros de Cruz das Armas/ Cristo Redentor/ Oitizeiro, região do Parque Arruda Câmara 
situado no bairro do Róger e adentrando nos bairros de Padre Zé e Treze de Maio, comunidade do Timbó localizado no bairro dos Bancários, comunidade Saturnino de Brito situado no bairro das Trincheiras e na comunidade Beira da Linha dos bairros do Alto do Mateus e Ilha do Bispo.

Os resultados obtidos a partir da comparação dos pontos das ocorrências de incêndios, através da análise visual e da análise estatística espacial validam positivamente as metodologias de Ribeiro (2008) e lógica Fuzzy utilizadas.

\section{Conclusões}

De acordo com os modelos apresentados, foi possível avaliar a vulnerabilidade de risco de incêndios com recurso a poucas variáveis e que são capazes de contribuir com o combate e controle das chamas na área de estudo.

A metodologia aplicada diagnosticou com precisão os locais onde devem-se tomar medidas para prevenção de tragédias, tornando possível estabelecer estratégias de maneira mais efetiva. A elaboração desse tipo de mapa pode se aplicar a áreas privadas e unidades de conservação, considerando as variáveis que influenciam o comportamento das chamas.

Os dados referentes ao segundo período sem chuvas apresentaram um maior risco, no qual a vegetação se encontrou bastante seca. $\mathrm{O}$ fator climático foi condicionante para o aumento das ocorrências de incêndios no período estudado, e que existiu certo grau de correlação entre o tamanho da população, área, densidade demográfica e o quantitativo de ocorrências de incêndios.

A análise de risco com a utilização da lógica fuzzy apresentou-se de forma satisfatória onde os modelos gerados apresentaram um $R^{2}$ acima de $85 \%$. A variável pluviometria contribuiu significativamente para que os modelos apresentassem maior confiabilidade. Essa variável não foi utilizada e nem recomendada na metodologia de Ribeiro et al (2008) e Chuvieco et al (2010).

Como fonte de informações seguras sobre a dinâmica do fogo, é notória a grande contribuição da aplicação da Estatística Espacial aliada ao geoprocessamento. As técnicas utilizadas mostraram utilidade na identificação de clusters de altos e baixos valores e áreas de transição entre os agrupamentos, sendo possível avaliá-los quanto ao nível de significância da associação espacial, destacando os grupos mais relevantes. Essa análise permitiu a extração informações adicionais que não são perceptíveis diretamente quando são utilizadas classificações e visualizações básicas.

A presença simultânea da alta declividade, vegetação, elevada densidade demográfica, baixo índice pluviométrico, aglomerados subnormais e áreas dentro da influência da rede viária e hidrografia contribuíram para o alto fator de risco de incêndios.

Para pesquisas futuras, recomenda-se testar pesos distintos nos modelos propostos por Chuvieco et al (2010) e Ribeiro et al (2008), além de se aplicar o mesmo para a lógica fuzzy.

Outra pesquisa poderia considerar o monitoramento e a análise temporal do modelo de predição gerado, modelos de simulação de propagação por meio de autômatos celulares, aplicação do método em áreas com grande incidência de raios e desenvolvimento de uma aplicação SIG multitemporal, pois as condições ambientais estão em mudanças constantes podendo alterar o fator de risco ao longo do tempo e garantindo com isso a confiabilidade dos resultados encontrados. 
Recomenda-se aos gestores a criação de uma política informativa para a população, com pequenos cuidados que podem ser tomados a fim de evitar prejuízos maiores. Estabelecer campanhas de sensibilização pública associadas à divulgação dos riscos, capacitação de pessoal para lidar com situações de perigo e o monitoramento contínuo das áreas consideradas mais propensas ao fogo, reordenamento do território em função do risco, elaborar diretrizes de ações estratégicas de acessos para atender as ocorrências. São atitudes que visam a segurança da população e evitam danos que podem ser causados pela ocorrência de incêndios.

\section{REFERÊNCIAS BIBLIOGRÁFICAS}

Alves, A.D.; Cunha, L.J.S. "Riscos Naturais Em Áreas Urbanas: Avaliação da Suscetibilidade em Santa Clara, Coimbra - Portugal". Revista da Casa da Geografia de Sobral, Sobral/CE, v. 18, n. 1, p. 63-83, Jul. 2016, http://uvanet.br/rcgs. ISSN 2316-8056.

Alves, K.M.A.S.; Nóbrega, R.S. “Uso de Dados Climáticos para Análise Espacial de Risco de Incêndio Florestal”. Revista Mercator, Fortaleza, v. 10, n. 22, p. 209-219, mai./ago. 2011.

Ambiente Brasil. "PREVFOGO Sistema Nacional de Prevenção e Combate aos Incêndios Florestais". Sítio Eletrônico. 2006. Disponível em: <http:// www.ambientebrasil.com.br>. Acesso em: 30 de março de 2012.

Barros, L. C.; Bassanezi, R. C. "Tópicos de Lógica Fuzzy e Bio-matemática”. Volume 5. Coleção IMECC. Textos Didáticos. IMECC - UNICAMP, Campinas. 2006.

Burrough, P. A.; Mcdonnell, R.A. "Principles of geographical information systems". Oxford, Oxford University Press, 2005.

Carvalho, M. S.; Câmara, G. "Análise de eventos pontuais". In Análise espacial de dados geográficos (eds. Drunck, S., Carvalho, M. S., Câmara, G. \& Monteiro, A. M. V.), 15 p. 2002. Disponível em: <http://www.dpi.inpe.br/gilberto/livro/analise/> Acessado em 15 de março de 2013.

Cecconello, M. S. “Modelagem alternativa para dinâmica populacional: Sistemas dinâmicos fuzzy”. Dissertação de Mestrado. IMECC- UNICAMP, Campinas. 2006.

Chou, Y. "Spatial autocorrelation of wildfire distribution in the Idyllwild Quadrangle, San Jacinto Mountains, California, USA”. Environmental Management, New York, v. 17, n. 1, p.129-140, 2010.

Chuvieco, E. A.; Yebra, I.; Nieto M.; Salas, H.; Martin, J.; Vilar, M.P.; Martínez, L.; Martín, J.; Ibarra, S.; De La Riva, P.; Baeza, J.; Rodriguez, J.; Molina, F.; Herrera, J. R.; Zamora, M. A. "Development of a framework for fire risk assessment using remote sensing and geographic information system Technologies”. Ecological Modelling 221: 46-58, 2010.

Clemente, R. "Algumas considerações sobre incêndios florestais". Geodésia Online. Florianópolis, 2008. Disponível em : 〈http://geodesia.ufsc.br〉. Acesso em: 28 de fevereiro de 2012.

Correia, G. "Elaboração de uma carta de Riscos de Incêndios Florestais aplicada ao município de Marituba - PA". Curso Superior de Tecnologia em Geoprocessamento. Instituto Federal de Educação, Ciência e Tecnologia - IFPB. João Pessoa. 52 p. 2007.

Ferraz, S.; Vetorazzi, C. "Identificação de áreas para recomposição florestal com base em princípios de ecologia de paisagem”. Revista Árvore, 27, 4p, Julho/Agosto, Viçosa. 2003. 
Koproski, L. P. "Importância do mapeamento de riscos de incêndios florestais para propriedades rurais”. 2007. In: IV Simpósio Sul-Americano Sobre Prevenção e Combate Aos Incêndios Florestais e $8^{a}$ Reunião Técnica Conjunta SIF/FUPE/IPEF sobre Controle de Incêndios Florestais. 2007, Belo Horizonte.

Koproski, L. P.; Nunes, J. R. S.; Beutling, A.; Melo, L. A. N.; Biondi, D.; Batista, A. C. "Relação entre a qualidade da paisagem e o risco de incêndios florestais". Revista Floresta, Curitiba, v. 38, n. 1, p. 145-154, jan./mar. 2008.

Koproski, L.; Ferreira, M. P.; Goldammer, J. G.; Batista, A. C. "Modelo de Zoneamento de Risco de Incêndios para Unidades de Conservação Brasileiras: O Caso do Parque Estadual do Cerrado (PR)". Revista Floresta, Curitiba, PR, v. 41, n. 3, p. 551-562, jul./set. 2011.

Lourenço, L.; Fernandes, S.; Bento-Gonçalves, A.; Castro, A.; Nunes, A.; Vieira, A. "Causas de incêndios florestais em Portugal continental. Análise estatística da investigação efetuada no último quinquênio (1996 a 2010)". Cadernos de Geografia no 30/31 - 2011/12 Coimbra, FLUC - pp. 6180 .

Machado, M. A. S.; Filho, P. S. B.; Medeiros, V. Z. "Um Sistema de Inferência Nebuloso para Apoio à Tomada de Decisão do Analista de Crédito de Empresas de Crédito Pessoal". RESI Revista Eletrônica de Sistemas de Informação. $7^{\mathrm{a}}$ Edição, Ano V, n. 1. 2006. P.1-25.

Mamdani, E. H.; Assilian, S. "An Experiment in Linguistic Synthesis with a Fuzzy Logic Controller”. International Journal Man-Machine Studies, vol. 7, n. 1, 1975. P. 1-15.

Minas Gerais, “Decreto $n^{\circ} 44.043 / 05$, de 09 de junho de 2005”. Cria o Programa de Prevenção e Combate a Incêndios Florestais, denominado Força Tarefa Previncêndio - FTP, para proteção das Unidades de Conservação, fragmentos florestais, reflorestamentos e estabelece as ações a serem desenvolvidas. MG: Diário do Executivo, 2005.

Nogueira, G. "Escolha de locais para instalação de torres de detecção de incêndio com auxílio do SIG”. Revista Árvore, Viçosa, v. 26, n. 3, p. 363-369, 2002.

Oliveira, D. "Zoneamento de risco de incêndios florestais no norte de Santa Catarina". Curitiba. 112 f. Dissertação (Mestrado em Engenharia Florestal) - Setor de Ciências Agrárias, Universidade Federal do Paraná, Curitiba, 2002.

Oliveira, S.; Oehler, F.; Ayanz, J.; Camia, A.; Pereira, J. "Modeling spatial patterns of fire occurrence in Mediterranean Europe using Multiple Regression and Random Forest”. Forest Ecology and Management, 2012, Vol.275, pp.117-129.

Pierce, A.; Farris, C. A.; Taylor, A. H. "Use of random forests for modeling and mapping forest canopy fuels for firebehavior analysis in Lassen Volcanic National Park, California, USA ”. Forest Ecology and Management, 2012, Vol.279, pp.77-89

Prudente, T. D. "Geotecnologias aplicadas ao mapeamento de risco de incêndio florestal no Parque Nacional da Chapada dos Veadeiros e área de entorno". Dissertação de mestrado. UFUMG. 114fl.: il. 2010.

Remmel, T. K.; Pereira, A. H. "Fire mapping in a northern boreal forest: assesssing AVHRR/NDVI methods of change detection ". Forest Ecology and Management, 152p., 119-129, 2001.

René, J. "Fuzzy Logic in Control”. Delft, The Netherlands. 1995. 322p.

Reyes, C. A. P. “Coevolutionary Fuzzy Modeling”. Tese de Doutorado. Écola Polytechnique Fédérale de Lausanne. Laussanne, Switzland. 2002. 162p. 
Ribeiro, L. "A Pressão Antrópica e os Riscos de Incêndios Florestais no Município de Novo Mundo, Amazônia Mato-Grossense". 2009. 132 f. Tese de Doutorado. Universidade Federal do Paraná, Curitiba. 2009.

Ribeiro, L.; Koproski, L.; Stolle, L.; Lingnau, C.; Soares, R.; Batista, A. “Zoneamento de Riscos de Incêndios Florestais para a Fazenda Experimental do Canguiri, Pinhais (PR)". FLORESTA, Curitiba, PR, v. 38, n. 3, jul./set. 2008.

Silva, T.B.; Franca Rocha, W.J.S.; Angelo, M.F. "Quantificação e análise espacial dos focos de calor no Parque Nacional da Chapada Diamantina - BA". Anais XVI Simpósio Brasileiro de Sensoriamento Remoto - SBSR, Foz do Iguaçu, PR, Brasil, 13 a 18 de abril de 2013, INPE

Silva, I. D. B.; Pontes, A. C. F. "Elaboração de um Fator de Risco de Incêndios Florestais utilizando Lógica Fuzzy". Revista Biomatemática 21. IMECC - UNICAMP - Campinas. 113128p. 2011. Disponível em: <http://www.ime.unicamp.br / biomat/bio21_art9.pdf>. Acesso em: 23 de julho de 2013.

Soares, R. V. "Incêndios florestais: controle e uso do fogo". Curitiba: FUPEF, 1985.

Takagi, T.; Sugeno, M. "Fuzzy Identification of Systems and Its Applications to Modeling and Control". IEEE Transactions on Systems, Man and Cybernetics, vol. 15, n. 1, 1985. P. 116-132.

Zhang, J.; Yao, F.; Liu, C.; Yang, L.; Boken, V. K. "Detection, Emission Estimation and Risk Prediction of Forest Fires in China Using Satellite Sensors and Simulation Models in the Past Three Decades - An Overview". International Journal of Environmental Research and Public Health, 2011, Vol.8 (8), p.3156-3178.

Received in February 22, 2017.

Accepted in August 11, 2017. 